\title{
Experimental Investigation of a Forward Swept Rotor in a Multistage Fan with Inlet Distortion
}

\author{
Aspi R. Wadia \\ GE Aviation, MD-S172, One Neumann Way, Cincinnati, OH 45215, USA \\ Correspondence should be addressed to Aspi R. Wadia, aspi.wadia@ge.com \\ Received 29 March 2011; Accepted 6 July 2011 \\ Academic Editor: Gecheng Zha
}

Copyright () 2011 Aspi R. Wadia. This is an open access article distributed under the Creative Commons Attribution License, which permits unrestricted use, distribution, and reproduction in any medium, provided the original work is properly cited.

Previous studies of transonic swept rotors in single stage fans have demonstrated the potential of significant improvements in both efficiency and stall margin with forward swept blading. This paper extends the assessment of the payoff derived from forward sweep to multistage configurations. The experimental investigation compare two builds of an advanced two-stage fan configuration tested alternately with a radial and a forward swept stage 1 blade. In the two-stage evaluations, the testing was extended to include the effect on inlet flow distortion. While the common second stage among the two builds prevented the overall fan from showing clean inlet performance and stability benefits with the forward swept rotor 1, this configuration did demonstrate superior front stage efficiency and tolerance to inlet distortion. Having obtained already low distortion sensitivity with the radial rotor 1 configuration relative to current production military fan standards, the sensitivity to inlet distortion was halved with the forward swept rotor 1 configuration. In the case of the 180-degree one-per-rev distortion pattern, the two-stage configuration was evaluated both with and without inlet guide vanes (IGVs). The presence of the inlet guide vanes had a profound impact in lowering the two-stage fan's sensitivity with inlet distortion.

\section{Introduction}

The trend in using aerodynamic sweep to improve the performance of transonic blading [1-8] has been one of the most significant technological evolutions for compression components in turbomachinery. Wadia et al. in [2] reported on the experimental evaluation and the subsequent analytical assessment of both aft and forward sweep compressor rotor technology with respect to aerodynamic performance and stability in a single-stage environment. The reduced shock/boundary layer interaction, resulting from reduced axial flow diffusion and less accumulation of centrifuged blade surface boundary layer at the tip, was identified as the prime contributor to the enhanced performance and aerodynamic stability with forward sweep.

Prompted by the single-stage results with the forward swept rotor, a program was started in 1993 at GE Aircraft Engines under the United States government sponsorship to pursue the performance benefits with forward sweep in multistage configurations. Most of this paper deals with the results and insights gained from these two-stage, low-aspectratio transonic fan tests including, for the first time, the effect of handling of inlet distortion with forward swept rotors.

In addition, in the case of the 180-degree one-per-rev inlet distortion pattern, the two-stage configuration was also evaluated both with and without inlet guide vanes. While no data has been published in the open literature on this subject, Hynes of Cambridge University [10] recalls the debate about the effect of inlet guide vanes on distortion tolerance/transmission in the late 1970s and the early 1980s. The US engine companies used inlet guide vanes on military fans while European companies did not. Hynes further recalls that in preliminary discussions of new applications, both sides claimed advantages for distortion tolerance, and as the European engines RB199 and EJ200 are collaborative ventures, there was much debate among the various European partners about whether to use them or not. According to Hynes, back-to-back tests were always a problem-the Europeans could never put a set of inlet guide vanes on their fans since they had taken advantage of the absence of the 
inlet guide vanes to design for much higher ratio of axial velocity to wheel speed. Any inlet guide vanes would have choked the annulus. In the USA a test without inlet guide vanes was not considered as they supported the forward fan bearing. Since then data with and without inlet guide vanes has been acquired by the US and European engine companies but has been kept proprietary. The data presented in this paper with and without inlet guide vanes, in the presence of inlet distortion, was acquired in this test series to respond to some of the above-mentioned concerns raised on both sides of the Atlantic Ocean.

To reduce costs, as many components as possible were used from an existing two-stage fan. The original advanced highly loaded base fan has no inlet guide vanes. It has a tandem type stator 1 with a variable flap to maintain the axial matching of the stages at off-design conditions. All the blade rows have conventional radial airfoils. This fan, known to the United States aircraft engine community as the high tip speed compressor (HTSC), was designed in 1981 by GE Aircraft Engines under the US Air Force contract and tested in the Compressor Research Facility (CRF) at the Wright Patterson Air Force Base (WPAFB), Ohio, USA. Details of the rig and some of these test results are reported by Rabe et al. [11], Hah et al. [12], and Manwaring et al. [13]. The GE swept forward aero research fan test vehicle (GESFAR) was a modification of this highly loaded two-stage fan. This was a cooperative program under the Integrated High Performance Turbine Engine Technology (IHPTET) initiative, in which the Navy sponsored GE Aircraft Engines to design a new integrally bladed forward swept first-stage rotor blade made of titanium. This was then tested backto-back with the original radial rotor configuration under both clean and distorted inlet flow conditions by the Air Force in the CRF at WPAFB. In a modular manner, the forward swept rotor configuration (GESFAR) also included a set of variable inlet guide vanes (a fixed front frame strut with a variable flap) to replicate current modern fighter engine fan configurations from both an aerodynamic and aeromechanical consideration. The fan rig design provided the flexibility to easily reconfigure the rig to its base configuration without the inlet guide vanes. As mentioned earlier in the paper, the base configuration without the inlet guide vanes used the tandem stator 1 with a variable flap to maintain the axial matching of the stages at off-design conditions. For the configuration with the inlet guide vanes present, the variable flap on the tandem stator 1 was fixed at its design setting.

\section{First-Stage Forward Swept Rotor Design}

The aerodynamic attributes of the two-stage fan are summarized in Table 1. Additional aerodynamic details can be obtained from Manwaring et al. [13].

To replicate the radial rotor aerodynamic design conditions, the forward swept rotor was also designed for the same flow path (i.e., without inlet guide vanes). The design point requirements of the forward swept front rotor were selected to preserve the internal stage matching with the radial rotor. The radial distributions of total pressure, total
TABle 1: Two-stage fan aerodynamic parameters.

\begin{tabular}{lc}
\hline Parameter & \\
\hline Inlet corrected tip speed, ft/sec, $(\mathrm{m} / \mathrm{sec})$ & $1609,(490.4)$ \\
Overall pressure ratio & 4.30 \\
Rotor 1 pressure ratio & 2.50 \\
Inlet corrected flow, $\mathrm{lbm} / \mathrm{sec},(\mathrm{Kgm} / \mathrm{sec})$ & $158.6,(71.95)$ \\
Flow/inlet annulus area, $\mathrm{lbm} / \mathrm{sec}-\mathrm{ft}_{2}$, & $42.3,(206.6)$ \\
$\left(\right.$ Kgm/sec- $\left.{ }_{2}\right)$ & 0.330 \\
Inlet radius ratio & $13.875,(35.2)$ \\
Rotor 1 inlet tip diameter, in, $(\mathrm{cm})$ & 1.694 \\
Rotor 1 inlet relative tip Mach number & 0.51 \\
Exit Mach number & 31.0 \\
Rotor 1 average hub slope, degrees & $1.02 / 1.30$ \\
Average aspect ratio (rotor/stator) & $1.77 / 1.77$ \\
Average pitch line solidity (rotor/stator) & $16 / 41$ \\
Number of rotor 1 blades/stator 1 vanes &
\end{tabular}

temperature, and the cascade internal passage area ratios were preserved for the forward swept rotor design. Although the thermodynamic properties at the inlet and discharge of the rotor had been retained, there were changes in the vector diagrams directly attributed to forward sweep. Most notable, and what is considered to be a signature of forward sweep, was the flow shift toward the tip. This flow shift is a strong contributor to the reduced aerodynamic loadings in the tip with the forward swept rotor. Due to this flow shift, stator 1 leading edge saw a slight increase in the absolute tip Mach number (lower in the hub region) with a corresponding reduction in tip incidence (increased stator leading edge incidence in the hub region).

The forward sweep was accomplished by moving the tip sections forward and into the direction of rotation in a manner similar to that described in the earlier paper by Wadia et al. [2]. Stringent mechanical constraints were placed on the forward swept rotor design to produce a configuration that represents a realistic aircraft engine product implementation, resulting in significant geometrical changes being made to the forward swept rotor relative to its radial counterpart. To compensate for the loss of effective load-carrying area in the root of the airfoil, the hub sections were $35 \%$ thicker than the radial blade. The maximum thickness in the tip region was also reduced on the forward swept blade to alleviate this problem. In general the forward swept rotor required significantly thicker leading edges and more forward positioning of maximum thickness to reduce the leading edge stresses. The thicker sections represent increased blade blockage and blunter leading edges with larger wedge angles. In spite of the added thickness and bluntness, proper mean camber line tailoring and shaping the hub flow path helped counter the compromise in performance due to mechanical design constraints with forward sweep. Leading edge sweep was also restricted by mechanical design to half the value of the forward sweep in the single-stage configuration (reported by Wadia et al. [2]) due to the increased tip speed of the two-stage fan. 


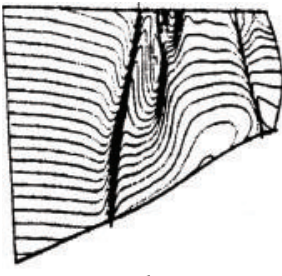

Pressure side

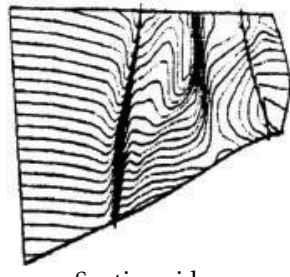

Suction side
Radial blade

(a)
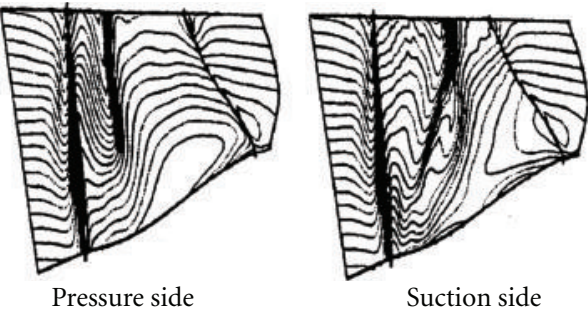

Forward swept blade

(b)

Figure 1: Surface isentropic Mach Numbers for the radial and forward swept stage 1 blades calculated at their common aerodynamic design point using a $3 \mathrm{D}$, single bladerow, viscous analysis.

The three-dimensional, single bladerow, viscous code used to analyze the single-stage configuration rotors [2] was used extensively in the design of the forward swept rotor 1 for the two-stage configuration. Even with thicker and blunter leading edges, the 3D viscous calculations yielded identical flow and efficiency levels with forward sweep relative to the radial blade. Figure 1 shows a typical comparison of the pressure and suction side isentropic Mach numbers for the two configurations. Again, in spite of its added thickness, the Mach number contours indicate a more started and oblique passage shock front with the swept forward blade. Using the $3 \mathrm{D}$ viscous analysis, based on a numerical stability criterion, the throttling capability (or range) of the forward swept design at design speed was calculated to be $6 \%$ better than its radial counterpart. This is consistent with the data for the forward swept rotor from the single-stage investigation. The $3 \mathrm{D}$ viscous analysis also showed no significant internal stage matching changes with the forward swept rotor, as confirmed by comparing the stage 1 stator inlet absolute Mach number and flow angle between the two configurations.

\section{Front Frame/Inlet Guide Vane Design}

To accomplish the IGV addition in a cost-effective manner, the front frame and inlet guide vane flaps were added after the design of the forward swept rotor 1 . The IGV addition was achieved by using an existing fan scale model rig front frame from the F120 program mated to a set of 15 zeroswirl flaps and flow path transition pieces. The fact that the existing front frame struts were cambered provided added aerodynamic design and configuration challenges to the IGV flap design.

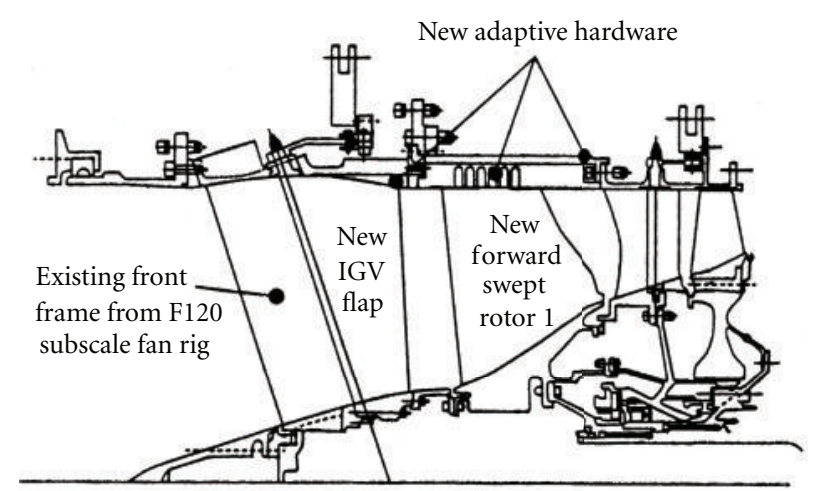

FIgURE 2: Test configuration showing the new adaptive hardware and the tandem stator 1 with variable flap from the original fan rig design.

The schematic of the fully assembled fan, showing the front frame with the IGV flap, the forward swept rotor 1, and the tandem stator 1 with the variable flap is shown in Figure 2. Addition of the existing front frame resulted in an aerodynamic compromise near the hub at the entrance to the stage 1 blade. The flow path curvatures were modified in this region to a decelerating type of curvature forcing redistribution of the flow and increasing the rotor hub leading edge incidence level. This increase in the leading edge incidence level is directly attributed to the addition of the front frame and inlet guide vanes after the design of the forward swept rotor 1. Detailed 3D viscous analysis using the forward swept rotor 1 configuration suggested a 1.5point reduction in the rotor efficiency due to the flow path differences.

\section{Test Setup and Instrumentation}

Back-to-back tests of the two-stage fan with the forward swept (GESFAR) and radial (HTSC) stage 1 blades were conducted by the Air Force in the CRF at WPAFB. The CRF is an open cycle test cell with a 20 -foot diameter test section. Atmospheric filtered air is drawn through five inlet valves that control inlet pressure. The data was acquired with depressed inlet pressure, especially during the stall testing of the machine.

The flow was measured using a calibrated venturi at the exit of the test section. Rotor exit total pressure and temperature measurements were made using steady state probes mounted on the leading edge of the first-and second-stage stators. Three stators, approximately spaced equally in the circumferential direction, were instrumented at seven radial locations. The fan exit total pressure and temperature data was recorded with arc rakes when running with clean inlet. There were seven immersions with each arc, encompassing two passages with ten circumferential elements. Casing static pressure instrumentation was provided over both stage 1 and stage 2 blades, with tip Kulites over stage 1 for dynamic pressure measurements.

Inlet total pressure distortion was created by screens located approximately 40 inches upstream of the hub 


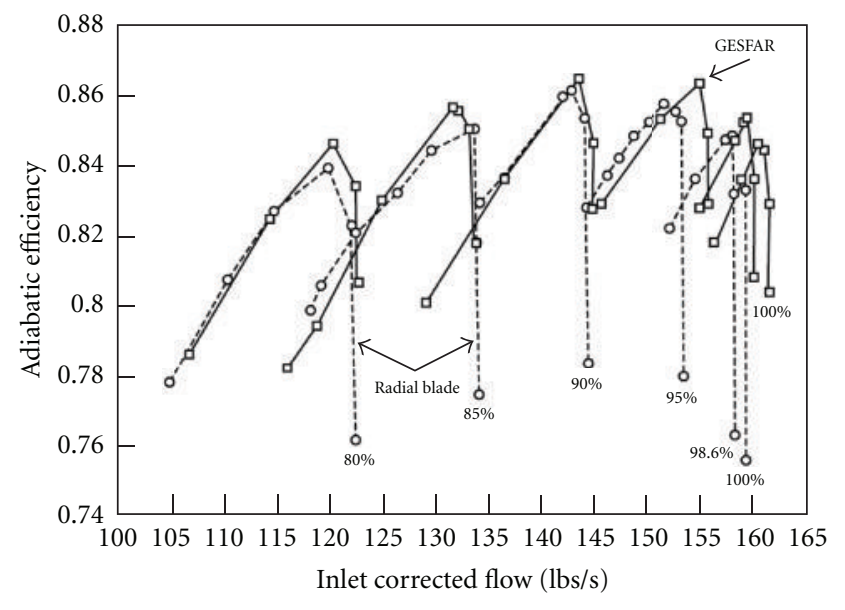

- o- Radial rotor configuration (HTSC)

$\neg-$ Forward swept rotor configuration (GESFAR)

(a)

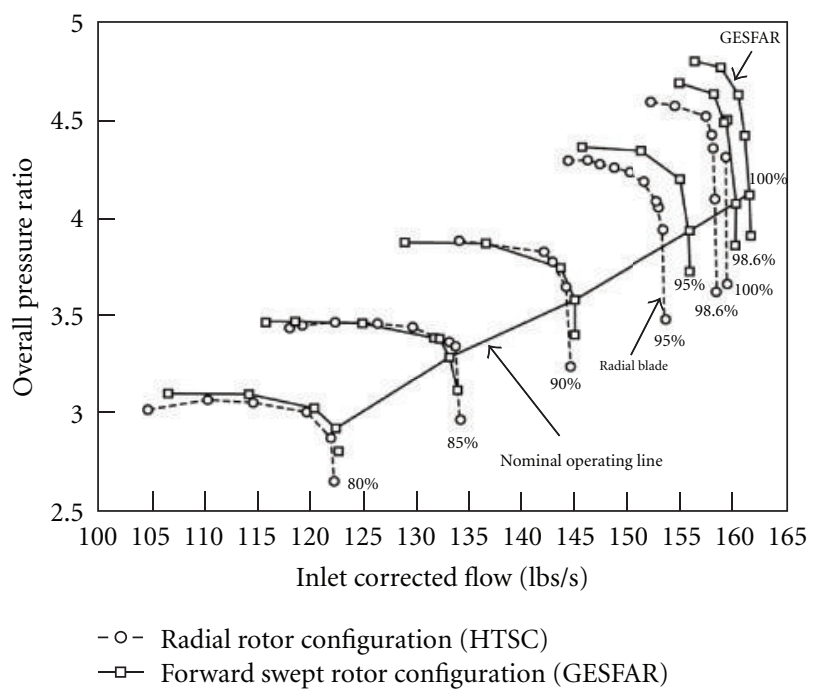

(b)

Figure 3: Comparison of measured overall fan performance with clean inlet and no front frame and IGVs between the radial rotor configuration (HTSC) and forward swept rotor configuration (GESFAR).

leading edge of the first stage rotor. Measurement of the inlet pressure profile with and without inlet distortion was obtained approximately 14.5 inches upstream from the same location with eight radial rakes. Each rake was equally spaced circumferentially with five radial total pressure measuring elements. These inlet total pressure measurements were averaged to obtain an average inlet total pressure. The inlet total temperature was measured using 49 thermocouples located at a measurement plane further upstream than the distortion screen location. An average inlet total temperature was calculated based on these thermocouples and was assumed to be constant from the measurement plane to the fan inlet for all test conditions.

When testing with inlet distortion, to get a more effective circumferential coverage at the fan exit, particularly when testing with one-per-rev patterns, the exit total pressure and temperature were measured using four radial rakes with seven radial combination probes per rake.

The measured average stage 1 blade running clearance at design speed with the forward swept rotor was 0.040 inches and 0.025 inches with the radial rotor. The second-stage rotor running clearance at design speed was estimated to be 0.050 inches. Based on the clearance derivatives for low-aspectratio transonic rotors previously obtained in the single-stage tests [2], the 0.015-inch larger clearance with the forward swept rotor 1 could contribute an additional 0.5 points in efficiency loss to its test-measured performance relative to the configuration with the radial rotor 1 . This performance upgrade adjustment has only been made to the performance data shown in the comparison of the efficiency between forward swept rotor 1 (GESFAR) and radial rotor 1 (HTSC) configurations with the front frame and IGVs in Figure 4. This efficiency adjustment is justified based on recent test data on an advanced multistage GE compressor with all forward swept rotors that demonstrated safe mechanical operation with lower tip clearances. However, no clearance difference adjustments were made to the stability margin comparisons.

A circumferential casing treatment insert was installed over the stage 1 blade with both rotor configurations, as shown for the forward swept rotor in Figure 2. Data was also acquired with a smooth casing during part of the test program, when running the forward swept rotor without IGVs.

To maintain the axial matching of the stages at off-design conditions, the inlet guide vanes were varied and tandem stator 1 with the variable flap was held fixed at its design setting when the rig was configured with IGVs. The tandem stator 1 with the variable flap was varied when the rig was configured without the IGVs.

\section{Overall Fan Performance without IGVs}

The overall performance of the two-stage fan with clean inlet and without the front frame and inlet guide vanes is presented in Figure 3. Recall that without the inlet guide vanes the tandem stator 1 with variable flaps was varied with speed to maintain the axial matching of the stages at off-design conditions. Comparison of the data between the forward swept rotor 1 configuration (GESFAR) and the radial rotor 1 configuration (HTSC) is shown in the figure. Due to time and test cost constraints, in this case only, there is a mixture of data. The data for the radial rotor 1 configuration was acquired with circumferential grooves over the stage 1 blade while the forward swept rotor 1 configuration during this phase of the test did not have circumferential grooves.

Even though both the radial and forward swept rotor configurations were designed for the same design point, the forward swept rotor exceeded the design speed mass flow of the radial rotor by $1.5 \%$. However, the similarity of the flow and pressure ratio levels achieved by both designs relative to the design point is within experience and is quite acceptable. 


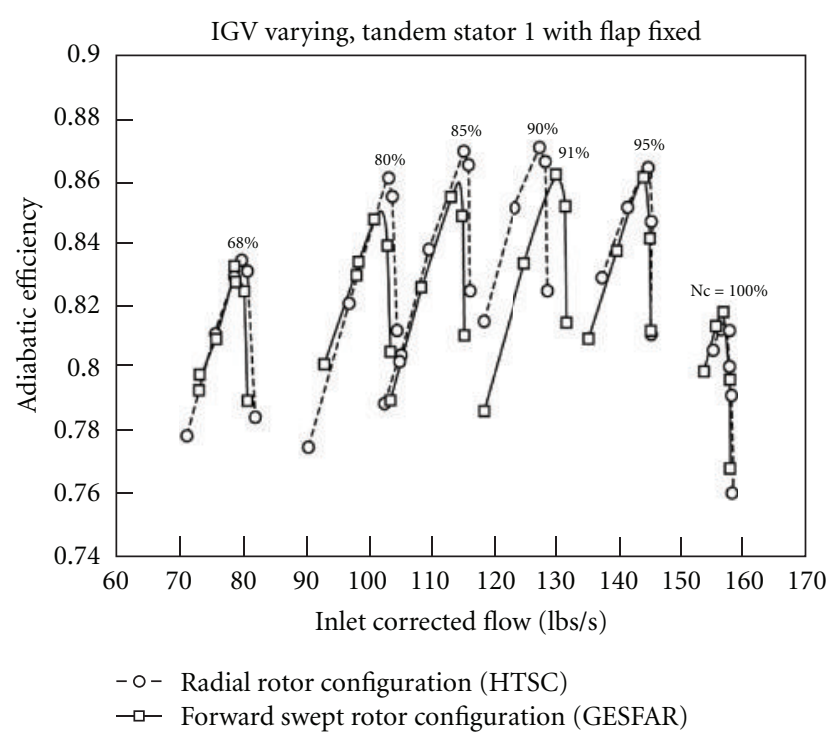

(a)

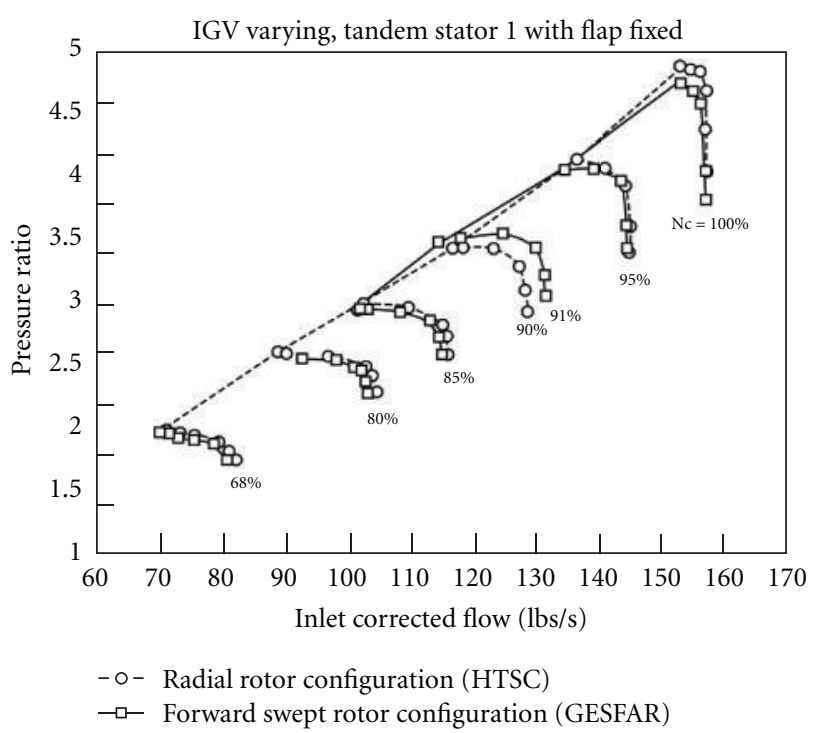

(b)

FIGURE 4: Comparison of the overall fan performance with clean inlet between radial rotor configuration (HTSC) and forward swept rotor configuration (GESFAR). Both configurations include front frame and IGVs and casing treatment over stage 1 blades.

The overall peak efficiency achieved by the forward swept rotor configuration is higher than that with the radial rotor configuration at all speeds. Some of this efficiency improvement, perhaps 0.25 points based on past experience, may be attributed to the smooth casing over the forward swept rotor relative to the circumferential grooves over the radial blade.

The measured high-speed stall line (based on the last steady state data point acquired before stall in Figure 3) was about the same for both blades, the forward swept rotor configuration obviously doing quite well even without the circumferential groove casing treatment. Analysis of the data suggested that the full potential for improved unstalled range

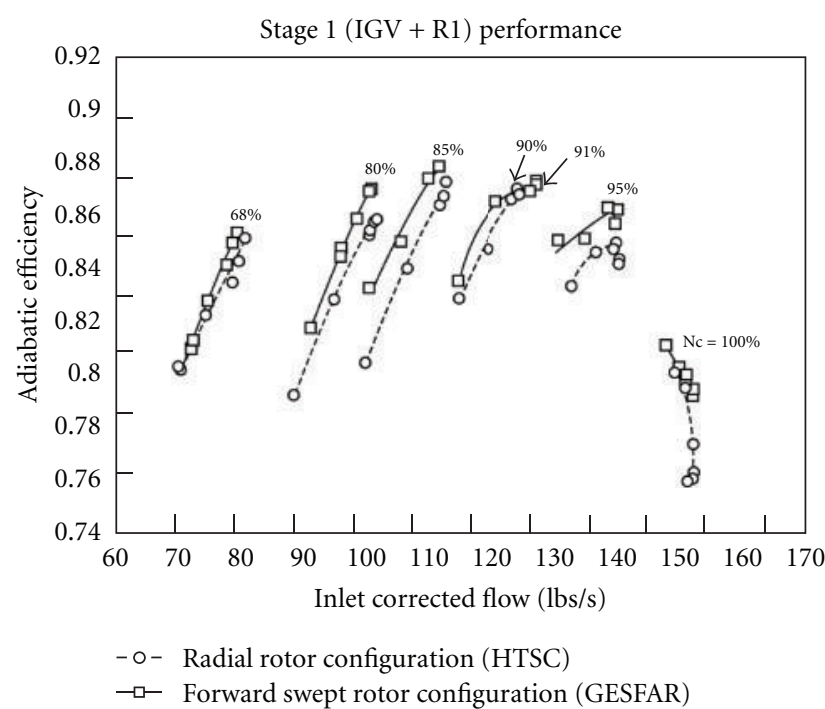

(a)

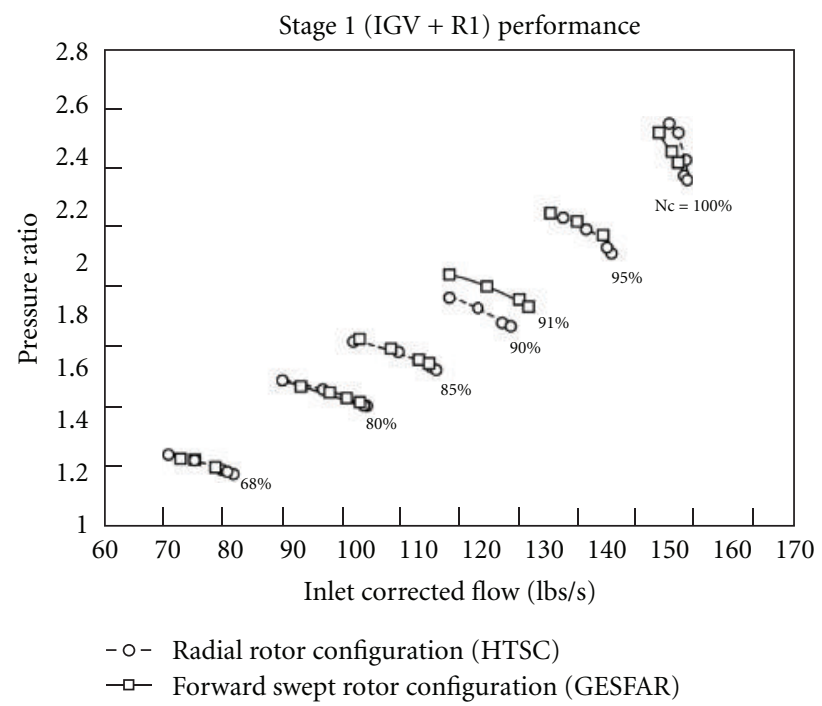

(b)

FIGURE 5: Comparison of IGV + rotor 1 group performance characteristic between the radial and the forward swept rotor 1 configurations.

with forward sweep may not have been fully realized at high speed because the second-stage rotor, common to both configurations, set the fan's high-speed stall limit with clean inlet. The measured part speed stall line at $85 \%$ and $90 \%$ inlet corrected speeds improved by as much as $6 \%$ with the forward swept rotor configuration despite the absence of casing treatment, the implication being that the stage 1 blade may be the limiting stage at lower speeds.

\section{Overall Fan Performance with IGVs}

The true back-to-back comparison of the measured overall performance of the fan with the forward swept rotor 1 configuration (GESFAR) and the radial rotor 1 configuration (HTSC) is presented in Figure 4. Both configurations used 


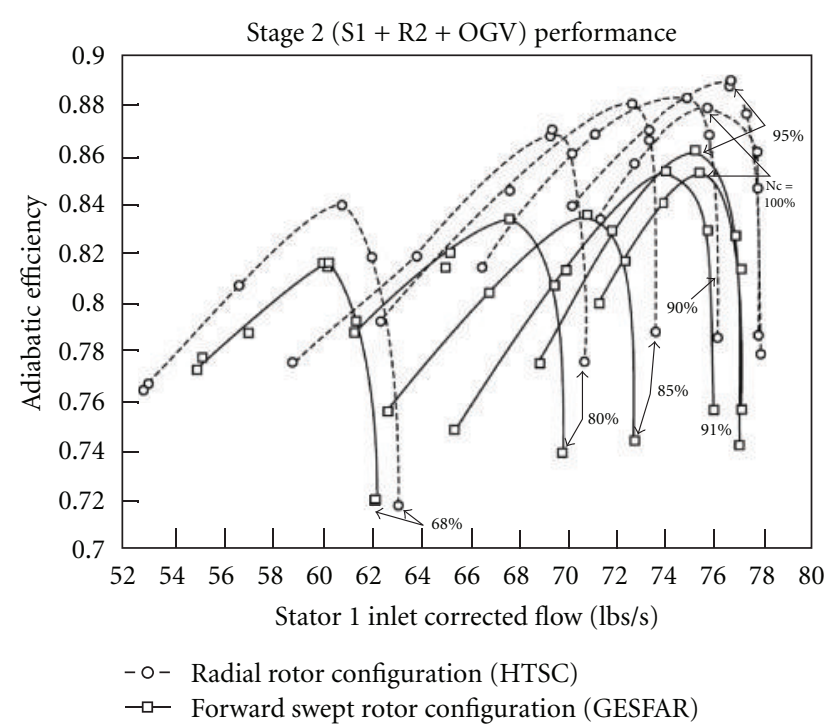

(a)

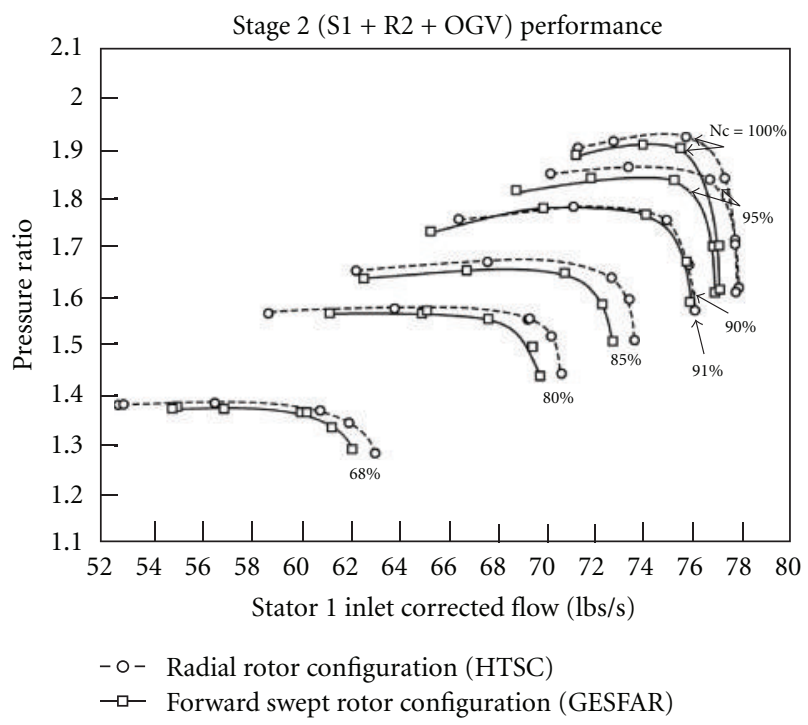

(b)

Figure 6: Comparison of stator $1+$ rotor $2+$ OGV group performance characteristic between the radial and forward swept rotor 1 configurations.

circumferentially grooved casing treatment over stage 1 blade and included the front frame with inlet guide vanes. The comparison of the overall adiabatic efficiency presented in Figure 4 shows the design speed peak efficiency to be slightly lower and the part speed peak efficiency to be about 0.5 to 0.7 points higher for the radial rotor configuration (HTSC) relative to the forward swept rotor configuration (GESFAR). As explained earlier, the forward swept rotor (GESFAR) efficiency data presented was adjusted upward to account for the stage 1 blade clearance differences between the two configurations. The high-speed clean inlet stall lines are practically unchanged between the two configurations.

Regarding the throttle limit capability shown in Figure 4, at inlet corrected speeds below $80 \%$, the forward swept rotor configuration was flutter limited and the fan could not be throttled up to stall. An additional IGV closure of about 15 degrees was required for the GESFAR rotor to be "stall protected," (i.e., no aeromechanical instability in the aerodynamically stable portion of the fan map), and this data obtained at the very end of the test is not presented here. The aeromechanical flutter appeared to be aggravated further with tip radial inlet distortion (i.e., total pressure lower at the casing) and was alleviated with hub radial inlet distortion (i.e., total pressure lower at the hub).

To identify the forward swept rotor 1 s contribution in the overall two-stage test results depicted in Figure 4, the stage performance results for the IGV + rotor 1 grouping and then for the stator $1+$ rotor $2+$ OGV grouping are shown in Figures 5 and 6, respectively. The inlet and the stator 1 leading edge measurements defined the IGV + rotor 1 group characteristics, while the stator 1 leading edge and the exit wake rake measurements were used to break out the stator 1 + rotor $2+\mathrm{OGV}$ performance.

Recognizing that one takes on certain risks in trying to rationalize in an absolute sense the measured overall performance using the interstage measurements, the comparisons were limited to data taken in a true back-to-back sense. While for this case the analysis results would have been more straightforward from comparisons of data with configurations without the IGVs, the lack of the true backto-back quality and to some extent data availability impelled us to do analysis based on data with the IGVs present.

The similarity of the speedline shapes and the speedflow characteristics shown in Figure 5 for the IGV + rotor 1 confirms the aerodynamic equivalence of the radial and swept rotor 1s. The as-measured efficiency comparison, also shown in Figure 5, gives a 0.5 - to 1.0-point advantage to the forward swept rotor 1 configuration. Although not shown, the performance improvements with the forward swept rotor are confined to the outer $50 \%$ (tip) of the annulus, similar to that observed in the single-stage test results [2]. The pressure ratio-flow characteristics details at each speed indicate that the forward swept rotor cannot get as unthrottled as the radial rotor in the two-stage environment and that at $100 \%$ speed the forward swept IGV + rotor 1 group has a slightly lower pumping (i.e., pressure ratio at flow) characteristic. Recall, during the design of the IGV system, the 3D viscous analysis indicated a performance derate due to the flow path differences. Perhaps this difference is more severe with the forward swept rotor configuration which results in the reduced pumping at $100 \%$ speed as seen in the data in Figure 5.

Although obtained with identical hardware, Figure 6 indicates lower pumping (pressure ratio at flow) and lower efficiency for the stator $1+$ rotor $2+$ OGV group with the forward swept rotor 1 configuration. This group's lower performance for the forward swept rotor configuration prevents the performance gains with forward sweep to materialize in the overall performance results shown in Figure 4. The more tip-strong radial profiles exiting from the forward swept rotor (higher tip pressure and cooler tip temperature) are thought to be the most likely cause for this. This is essentially equivalent to imposing a hub 
radial inlet distortion (i.e., lower total pressure at the hub) into the second stage, which from past experience with this machine has shown the tendency to reduce the peak flow and pressure rise capability along a constant speed characteristic as well as derate the performance. It should be pointed out that the speed lines in Figure 6 represent constant inlet corrected speeds and not stage 2 corrected speeds. The reduced maximum corrected flow capability of the stator 1 + rotor $2+$ OGV group with the forward swept rotor 1 in combination with the higher flow pumping of the forward swept rotor 1 indicated in Figure 3 is the cause for the swept rotor higher minimum operating line compared to the radial rotor's in the two-stage environment that was noted earlier in Figure 5. Figure 6 also shows that at the 95\% and 100\% inlet corrected speeds, nearly identical maximum corrected flow into the stator $1+$ rotor $2+\mathrm{OGV}$ group is obtained. This is a result of the IGV + rotor 1 group's declining performance and an increase in the annulus/wake blockage.

Interstage Kulites indicated stage 2 to be the stalling stage at and above $85 \%$ corrected speed with clean inlet. This prevented the forward swept rotor 1 from demonstrating any possible aerodynamic stability enhancement with clean inlet in the two-stage environment. The individual stage performance shown in Figures 5 and 6 was further investigated by a $3 \mathrm{D}$ viscous analysis of the front and rear rotors of the forward swept rotor configuration (GESFAR) operating at design speed near peak efficiency. The calculated isentropic Mach number contours at $10 \%$ immersion from the tip endwall for both rotor 1 and rotor 2 are shown in Figure 7(a). The forward swept stage 1 blade has a well-defined passage shock with a weak leading edge compression wave, suggesting the availability of significantly more range before stall. On the other hand, the detached leading edge shock structure on rotor 2 translates into a flow rollover condition (seen in the stage 2 data in Figure 6), resulting in lower fan efficiency with further throttling of the fan. For comparison with the analytical results, test results measured by over the tip Kulites are presented in Figures 7(b)-7(d). These were available for rotor 1 only and are in an isobar format as opposed to the constant ideal Mach number lines of Figure 7(a). Although the analytical investigation was done only at the design speed peak efficiency condition, the test data is provided at three corrected speeds, $100 \%, 95 \%$, and 91\%, and three throttle conditions, peak efficiency, near stall, and halfway between peak efficiency and stall (Near Stall +0.5$)$. Both the analytical and the test results at the design speed at peak efficiency condition qualitatively show a started and reflected passage shock system. On a more detailed basis, the test data indicates a reduced obliqueness for the front shock and reduced strength for the reflected leg of the shock system. Hence the test data indicates a higher level of throttling for rotor 1 than the data match results, which could be the result of allocating too low a loss level in the data match for the inlet guide vanes. On a comparative basis, the shock migrations depicted in Figures 7(b)-7(d) for rotor 1 between the peak efficiency and the near-stall condition (see Figure 4) indicate progressively more throttling for rotor 1 between these two throttle conditions as the corrected speed is reduced.

\section{Overall Stability with Inlet Distortion}

An excellent tutorial survey of the effects of inlet flow distortion on engine performance and stability has been presented in an AGARD lecture series by Longley and Greitzer [9]. A key objective of this program was to evaluate the effects of inlet distortion on the stall margin of the twostage fan with both the forward swept rotor 1 and the radial rotor 1 configurations. As stated by Longley and Greitzer that although the distortions encountered are generally $3 \mathrm{D}$, it is extremely useful to break them at least conceptually, into radial and circumferential nonuniformities and approach each separately. A total of five distortion screens were used in this investigation. Three of the five screens had either radial or circumferential inlet distortion patterns. The other two screens were a combination of the radial and circumferential distortions.

A typical fan map comparing clean inlet data with inlet distortion data using a distortion screen with a combined pattern (tip radial + one-per-rev referred to as tip/rev) for the forward swept configuration (GESFAR) is presented in Figure 8. A slight loss in flow and peak pressure ratio was observed in the presence of inlet distortion. The data shows a minor loss in high-speed stall line and a small gain in part speed stall line with inlet distortion. Stall line comparisons between clean and distorted inlet for the forward swept rotor configuration (GESFAR) with the other distortion screens show similar trends. In general, the forward swept rotor showed a significant tolerance to inlet distortion.

The fan sensitivity with inlet distortion was calculated in the following manner. A parameter, DPRS, was defined as

$$
\mathrm{DPRS}=1.0-\left(\frac{\mathrm{PRSD}}{\mathrm{PRSC}}\right)
$$

where PRSD is the overall fan pressure ratio at stall with inlet distortion and PRSC is the overall fan pressure ratio at stall with clean inlet. The inlet distortion index for circumferential distortion, IDC, was calculated using the inlet distortion rakes as

$$
\mathrm{IDC}=1.0-\left(\frac{\mathrm{PM}}{\mathrm{PFA}}\right)
$$

where PM is the minimum total pressure and PFA is the face averaged total pressure (area averaged). Similarly, the inlet distortion index for radial distortion, IDR, was computed using the inlet distortion rakes as

$$
\mathrm{IDR}=1.0-\left(\frac{\mathrm{PMR}}{\mathrm{PFA}}\right),
$$

where PMR is the ring averaged total pressure (area averaged) and PFA is the face averaged total pressure (area averaged). Using (1) and (2) the fan sensitivity, SENS, with circumferential distortion was then defined as

$$
\mathrm{SENS}=\frac{\mathrm{DPRS}}{\mathrm{IDC}}
$$

and similarly using (1) and (3), the fan sensitivity with radial distortion was defined as

$$
\mathrm{SENS}=\frac{\mathrm{DPRS}}{\mathrm{IDR}},
$$




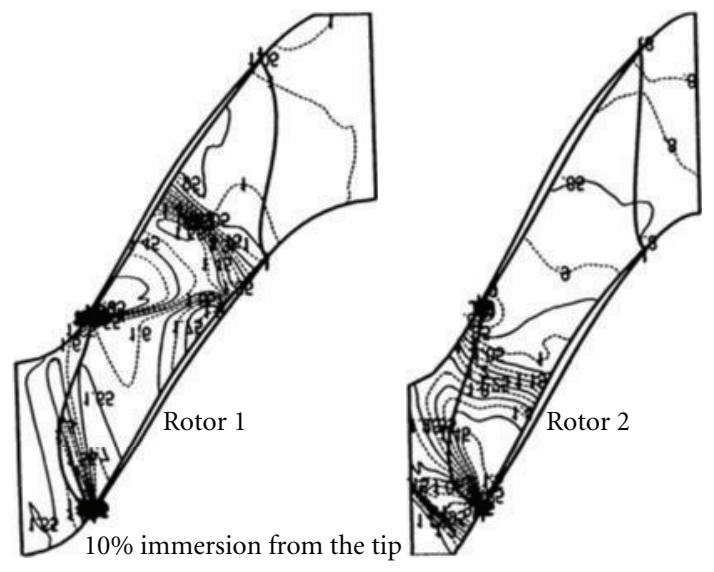

3D viscous analysis of GESFAR configuration (design speed near peak efficiency)

(a)

GESFAR circumferential grooves and IGVs

Fan tip static pressure ratio contours 95\% Nc

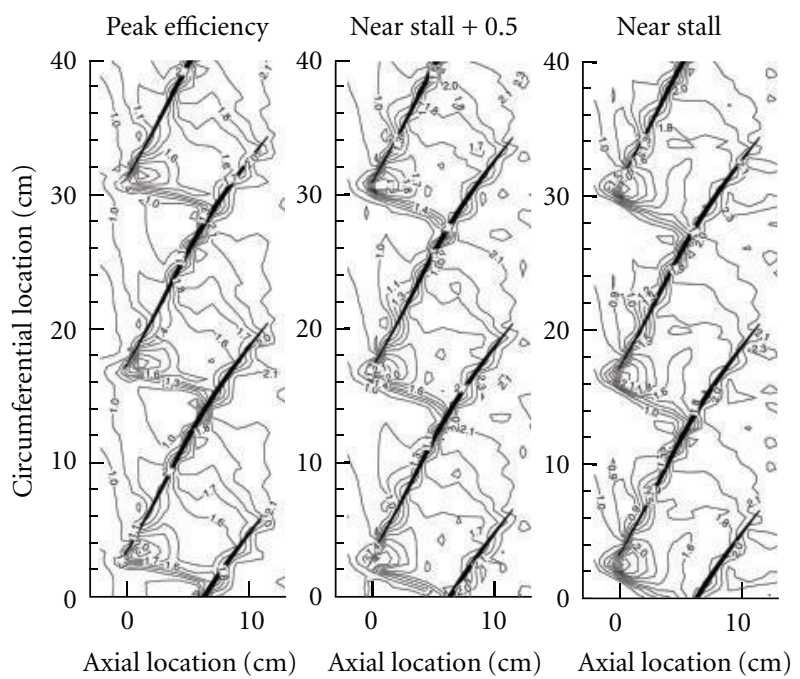

(c)
GESFAR circumferential grooves and IGVs

Fan tip static pressure ratio contours 100\% Nc

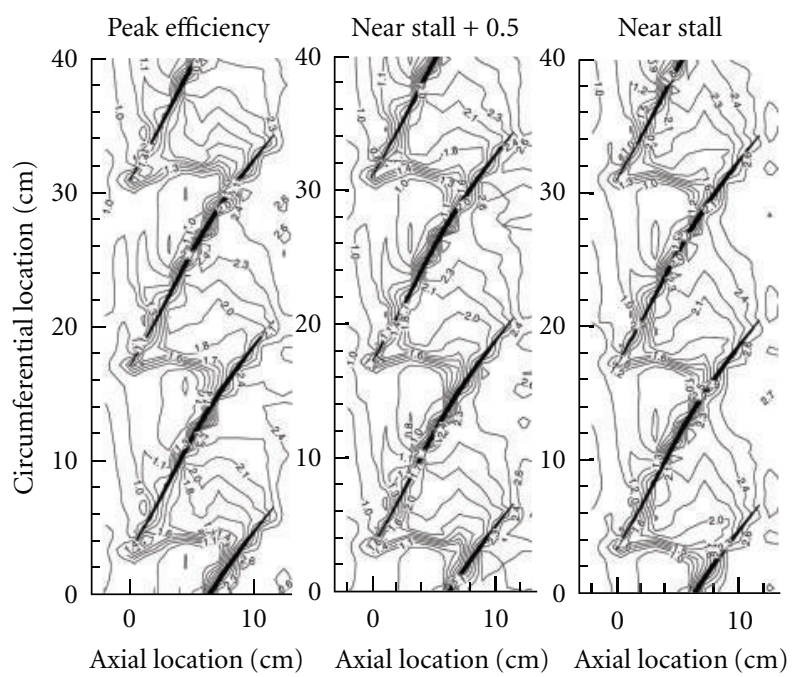

(b)

GESFAR circumferential grooves and IGVs Fan tip static pressure ratio contours $91 \% \mathrm{Nc}$

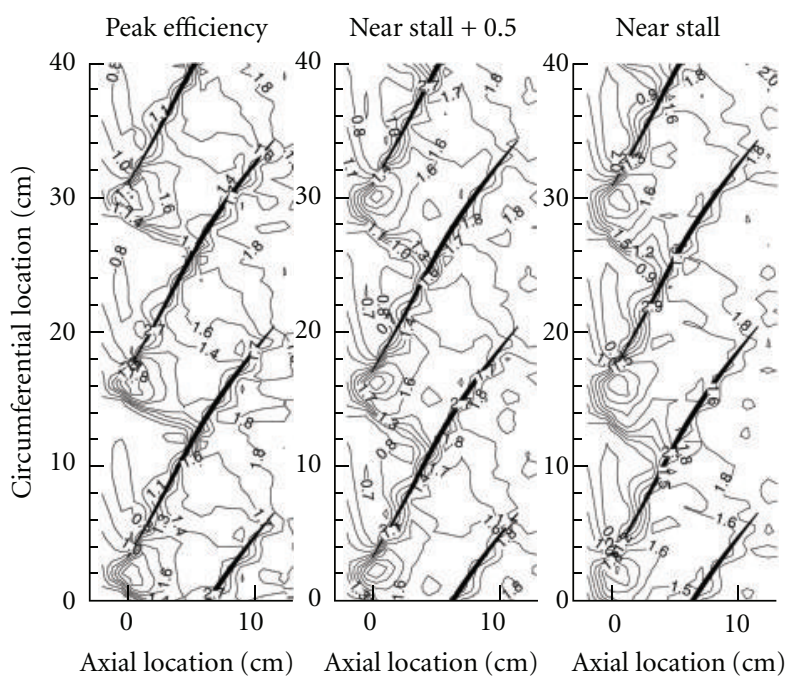

(d)

Figure 7: (a): Isentropic Mach Number contours at rotor tip calculated using a 3D viscous analysis of the data for stage 1 and stage 2 rotors for the forward swept configuration (GESFAR) at design speed near peak efficiency, (b): Tip kulite data over rotor 1 at design speed at three throttle settings, (c): Tip kulite data over rotor 1 at 95\% speed at three throttle settings and (d): Tip kulite data at $91 \%$ speed at three throttle settings.

Figure 9 shows the percent change in fan sensitivity of the forward swept rotor configuration (GESFAR) relative to that with the radial rotor configuration (HTSC), calculated by the formula in (6), for all five distortion screens

$\%$ SENS change

$$
=\frac{(\text { GESFAR SENS }- \text { HTSC SENS })}{\text { HTSC SENS } \times 100} .
$$

For the five screens tabulated along the horizontal axis as shown in this figure, the percent change in sensitivity relative to the radial rotor configuration (HTSC) is shown along the vertical axis. The magnitude of the distortion indices of each screen in Figure 9, on the nominal operating line at design speed with inlet guide vanes, can be categorized from moderate to high. These were calculated from (2) and (3) using data from the inlet distortion rakes and by rotating the distortion screen through 360 degrees at 22.5-degree intervals.

While the common second stage among the two rotor 1 configurations prevented the overall fan from showing 


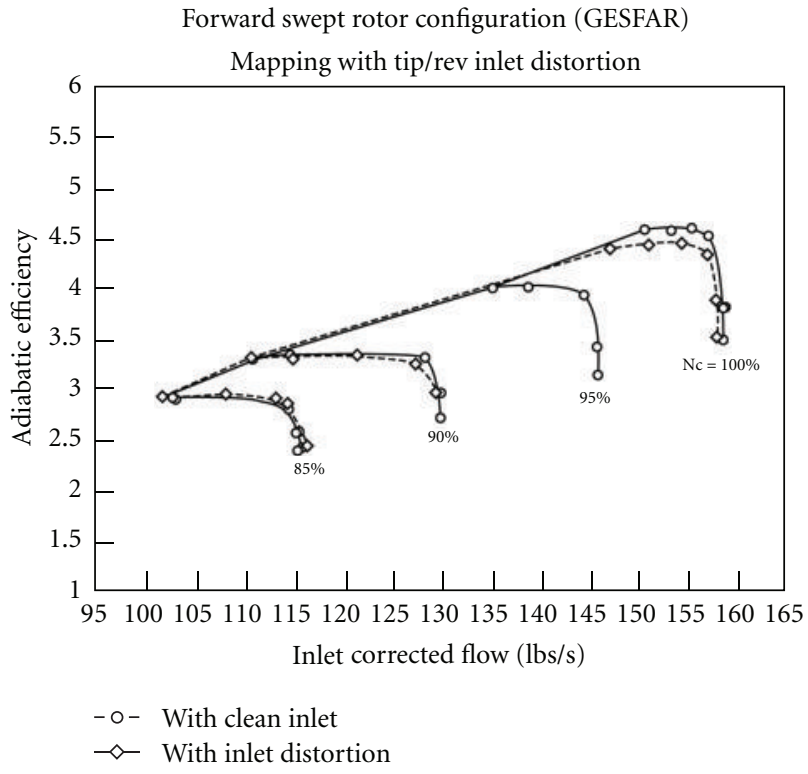

Figure 8: Comparison of the fan maps with clean inlet data and with tip/rev inlet distortion data for the forward swept rotor configuration (GESFAR).

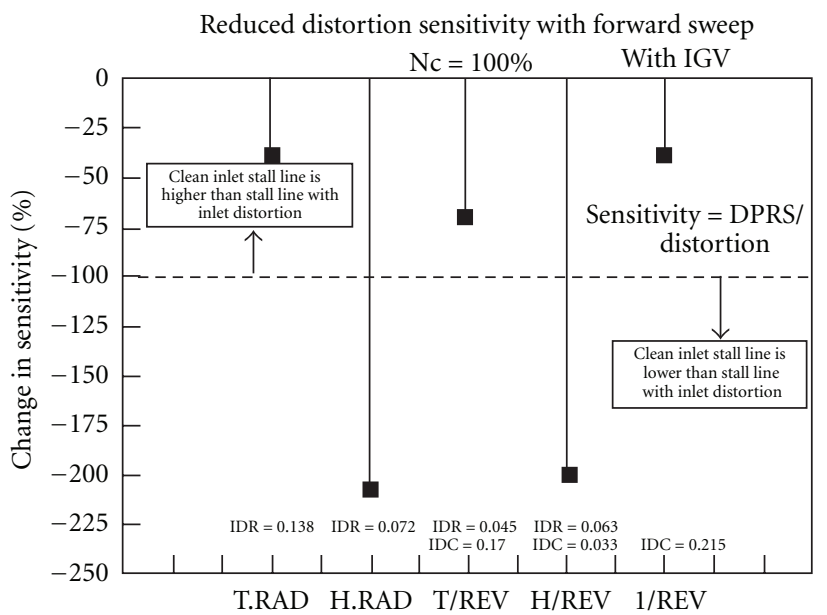

FIGURE 9: Relative distortion sensitivity between the radial (HTSC) and the forward swept (GESFAR) rotor configurations.

significant clean inlet performance and stability benefits; the forward swept rotor 1 configuration (GESFAR) did demonstrate superior front stage efficiency (Figure 4) and tolerance to inlet distortion. Having obtained an already low distortion sensitivity with the radial rotor 1 configuration (HTSC) relative to current military fan standards, the sensitivity to inlet distortion was halved with the forward swept rotor 1 configuration (GESFAR), as shown in Figure 9. The negative values shown in the figure indicate that the sensitivity to inlet distortion with the forward swept rotor configuration (GESFAR) was always less than the sensitivity to inlet distortion with the radial rotor configuration (HTSC). With the tip radial (T.RAD), the tip-per-rev (T/REV), and the oneper-rev (1/REV) inlet distortion, the forward swept rotor configuration (GESFAR) always lost less stall line (relative to its clean inlet stall line) than the radial rotor configuration (HTSC).

It was generally felt that the forward swept rotor with its inherent tendency to have flow migration to the tip would do well with a tip radial screen. It was however unclear if this would adversely impact the inlet distortion handling capability of the forward swept rotor configuration with a hub radial screen. Figure 9 shows that the fan sensitivity with hub radial inlet distortion was not compromised with forward sweep. In fact, with the hub radial (H.RAD) and the hub-per-rev (H/REV) inlet distortion, the forward swept rotor configuration (GESFAR) showed as much of an improvement in the stall line (relative to its clean inlet stall line) as the relative loss in stall line with the radial rotor configuration (HTSC) resulting in the percent change in sensitivity values to exceed 200 as shown in Figure 9.

\section{Effect of IGVs on Performance}

The use of inlet guide vanes has been a highly debated subject [10] for military fans that have to cope with large amounts of distortion due to complex inlets and aircraft maneuvers. For the forward swept rotor configuration (GESFAR), test data acquired to determine the impact of the front frame/IGVs and the casing treatment over stage 1 blade on the overall performance of the fan is presented in Figure 10. Recall that when the IGVs are present, the fan tandem stator 1 with its variable flap is fixed at its design point setting and the IGV closes (i.e., flaps move in the direction of rotor rotation) with a reduction in corrected speed. When the IGVs are not present, the variable flap on the tandem stator 1 is variable, tending to have a more open (i.e., opposite to rotor rotation) setting with a reduction in corrected speed.

Mainly due to the different variable geometry actuation strategy with and without inlet guide vanes as stated in the above paragraph, the flow at speed was significantly altered with the IGVs. At design speed, where the IGVs were meant to replicate the no-IGV zero swirl inlet condition, the flow was reduced by $2.5 \%$; at part speed, where the IGVs are closed, the reduction in flow was as much as $18 \%$. In addition to the loss in flow, the addition of the IGVs and casing treatment resulted in an overall loss in peak fan efficiency at design speed of approximately 4 points. High Mach numbers, possibly choking in the IGV, and the previously mentioned $3 \mathrm{D}$ analysis that identified performance penalties with the IGVs due to the flow path differences are responsible for this. The IGVs, as expected, improved the fan efficiency at part speed.

Design speed stall margin with IGVs, on the other hand, increased by $4 \%$. However, the results shown in Figure 10 suggest that the IGVs had little or no influence on the stall line with clean inlet below $90 \%$ speed. This further suggests that the second stage rotor is setting the fan stall limit, thus restricting the full potential benefit of the IGVs and forward sweep from materializing.

Although clouded by the absence of casing treatment over rotor 1, the presence of the IGVs was found to reduce the 


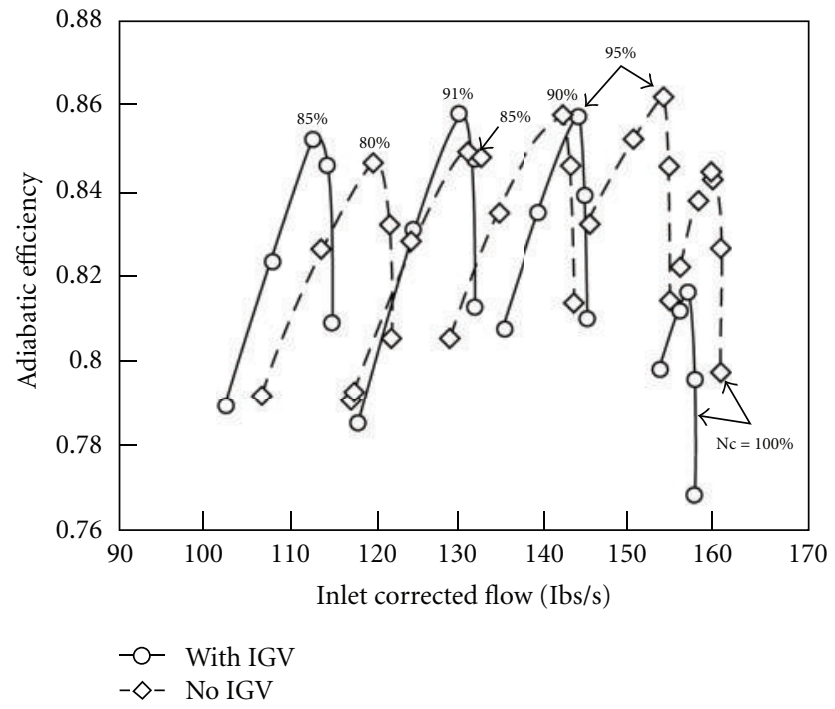

(a)

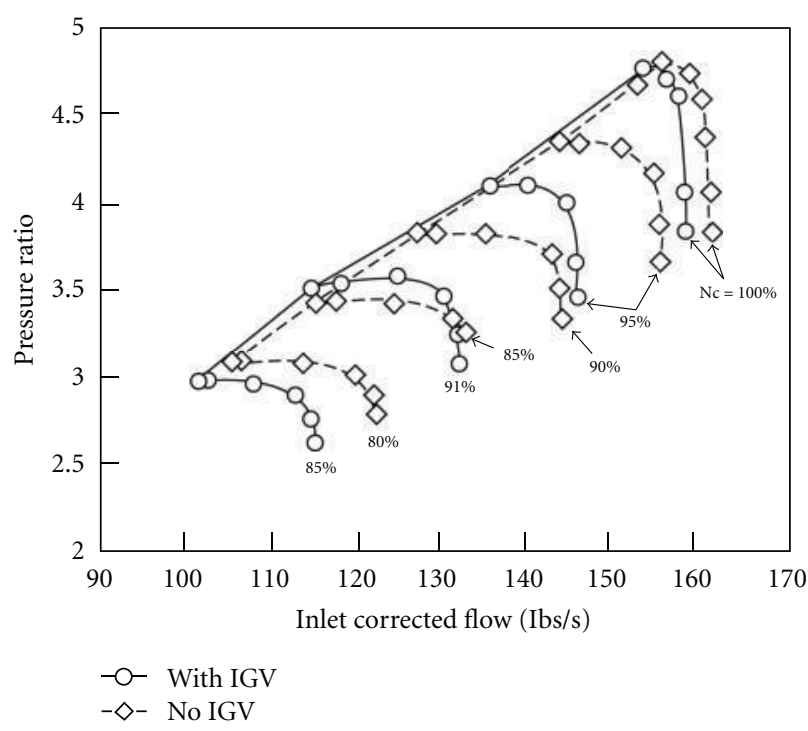

(b)

FIGURE 10: Comparison of overall fan performance for the forward swept rotor configuration (GESFAR) with and without the front frame and IGVs.

forward swept rotor configuration (GESFAR) fan sensitivity to 180 degree one-per-rev inlet distortion by $42 \%$. This degree of reduction in the sensitivity is even more remarkable when one considers the fact that the IGV-less base sensitivity is already very low relative to current military fan technology levels. The reason for this improvement is thought to be associated with the elimination or reduction in the inlet swirl level that is indited by the one-per-rev distorted inlet flow field when the IGVs are present. Due to the in phase one-perrev static pressure distortion that accompanies a one-per-rev total pressure distortion in the inlet, an opposing symmetric inlet swirl field is indited by the flow migration from the high static pressure to the low static pressure region. Accordingly, half the annulus is imparted swirl velocity in the direction of rotor rotation and half in the direction opposite to rotor rotation. This carries on to the inlet of rotor 1 unless there are IGVs present to eliminate or greatly reduce it. In a parallel compressor sense, the low-pressure sector with swirl in the direction of rotor rotation will provide the weakest link, due to its impaired capability relative to the other sectors to achieve the common discharge static pressure level.

\section{Concluding Remarks}

After assessing the impact associated with each direction of sweep in a single-stage environment reported in an earlier paper, the research into swept rotor technology was expanded to include the effects of forward sweep in a twostage fan. This program also included evaluating the effect of sweep on the handling of inlet distortion and to evaluate the effect of inlet guide vanes on fan performance and stability.

The investigation was conducted on a back-to-back basis using a radial and a forward swept stage 1 blade in the two-stage configuration. The common second stage between the two configurations prevented the overall fan from showing clean inlet performance and stability benefits with the forward swept rotor 1. However, the forward swept rotor configuration (GESFAR) was shown to possess superior front stage efficiency and tolerance to inlet distortion. The distortion sensitivity was halved with the forward swept rotor 1 . The forward swept rotor configuration improved the sensitivity with inlet distortion that included tip and hub radial screens, a 180-degree one-per-rev screen and two combined patterns that contained a tip/rev and a hub/rev screen. The test results supported the hypothesis that the forward swept rotor 1 configuration produces a better flow field in the tip region and was expected to improve the sensitivity with the tip radial patterns. It was surprising that this feature of forward sweep did not result in a negative impact on the fan sensitivity with hub radial inlet distortion.

The key benefits of the IGVs were identified with tests with and without IGVs for both clean inlet and with the 180-degree one-per-rev inlet distortion pattern. While the IGVs did result in a large efficiency penalty, at design speed the improvement in fan sensitivity with inlet distortion was significant. The improvement was specifically due to the reduction or elimination of the induced inlet swirl.

The aerodynamic implications with radial and forward swept blading have been explored in great detail on a backto-back basis in this paper and the earlier companion paper. The overall test results suggest some unique improvements to efficiency with some substantial improvements to the sensitivity to inlet distortion with forward swept blading. Further efforts are now underway to study the effect of redesigning the second stage rotor with forward sweep, and implementation of this technology into advanced highly loaded compressors in aircraft engines is well underway.

\section{Nomenclature}

DPRS: $1.0-($ PRSD/PRSC)

IDC: Circumferential inlet distortion index $=(1-$ PM/PFA) 
IDR: Radial inlet distortion index $=(1-\mathrm{PMR} / \mathrm{PFA})$

IMM: Radial immersion ( $0=$ tip, $1=$ hub $)$

P: $\quad$ Pressure

PFA: $\quad$ Face averaged total pressure (area averaged)

PM: Minimum total pressure

PMR: Minimum ring averaged total pressure (area averaged) when in the hub, referred to as hub radial distortion (total pressure is lower at the hub) and when in the tip, referred to as tip radial distortion (Total Pressure is lower at the tip)

PR: Overall fan pressure ratio

PRS: Overall fan pressure ratio at stall

PRSC: Overall fan pressure ratio at stall with clean inlet

PRSD: Overall fan pressure ratio at stall with inlet distortion

SENS: Fan sensitivity $=($ DPRS/inlet distortion index $)$.

\section{References}

[1] N. Yamaguchi, T. Tominaga, and J. Masutani, "Performance improvement by forward-skewed blading of axial fan moving blades," in Proceedings of the 11th International Symposium on Air Breathing Engines (ISABE '93), pp. 580-589, Tokyo, Japan, 1993, ISABE Paper 93-7055.

[2] A. R. Wadia, P. N. Szucs, and D. W. Crall, "Inner workings of aerodynamic sweep," in Proceedings of the International Gas Turbine \& Aeroengine Congress \& Exposition, June 1997, ASME Paper No. 97-GT-401.

[3] J. D. Denton and L. Xu, "The effects of lean and sweep on transonic fan performance," in Proceedings of the ASME TURBO EXPO: Turbomachinery, pp. 23-32, June 2002, ASME Paper 2002-GT-30327.

[4] H. Passrucker, M. Engber, S. Kablitz, and D. K. Hennecke, "Effect of forward sweep in a transonic compressor rotor," Proceedings of the Institution of Mechanical Engineers, Part A: Journal of Power and Energy, vol. 217, no. 4, pp. 357-366, 2003.

[5] G. S. McNulty, J. J. Decker, B. F. Beacher, and S. A. Khalid, "The impact of forward swept rotors on tip clearance flows in subsonic axial compressors," Journal of Turbomachinery, vol. 126, no. 4, pp. 445-454, 2004.

[6] J. Bergner, S. Kablitz, D. K. Hennecke, H. Passrucker, and E. Steinhardt, "Influence of sweep on the 3D shock structure in an axial transonic compressor," in ASME Turbo ExpoGas Turbie Technology: Focus for the Future, pp. 343-352, June 2005, ASME Paper GT2005-68835.

[7] E. Benini and R. Biollo, "Aerodynamics of swept and leaned transonic compressor-rotors," Applied Energy, vol. 84, no. 10, pp. 1012-1027, 2007.

[8] P. V. Ramakrishna and M. Govardhan, "Combined effects of forward sweep and tip clearance on the performance of axial flow compressor stage," in ASME Turbo Expo, pp. 273-282, June 2009, ASME Paper GT2009-59840.

[9] J. P. Longley and E. M. Greitzer, "Inlet distortion effects in aircraft propulsion system integration," in Fundamentals and Special Problems of Synthetic Aperture Radar (SAR), AGARD Lecture Series, 1993, AGARD LS-183.

[10] T. P. Hynes, private communication, 2001.

[11] D. Rabe, A. Boles, and P. Russler, "Influence of inlet distortion on transonic compressor blade loading," in Proceedings of the 31st AIAA/ASME/SAE/ASEE Joint Propulsion Conference, San Diego, Calif, USA, 1995, AIAA Paper No. 95-2461.

[12] C. Hah, D. C. Rabe, T. J. Sullivan, and A. R. Wadia, "Effects of inlet distortion on the flow field in a transonic compressor rotor," in Proceedings of the International Gas Turbine and Aeroengine Congress \& Exhibition, p. 18, June 1996, ASME Paper No. 96-GT-547.

[13] S. R. Manwaring, D. C. Rabe, C. B. Lorence, and A. R. Wadia, "Inlet distortion generated forced response of a low aspect ratio transonic fan," in Proceedings of the International Gas Turbine and Aeroengine Congress \& Exhibition, p. 14, June 1996, ASME Paper No. 96-GT-376. 

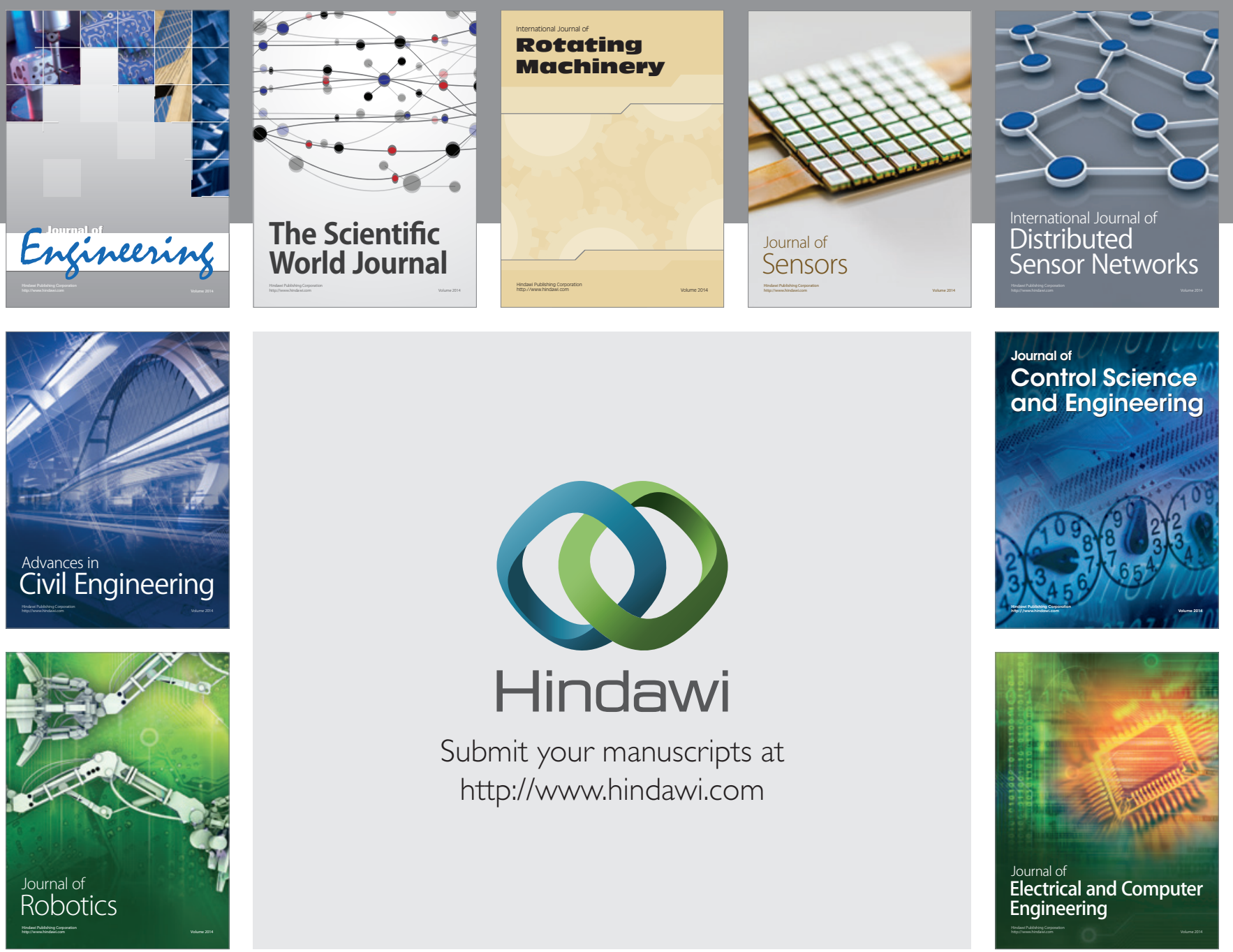

Submit your manuscripts at

http://www.hindawi.com
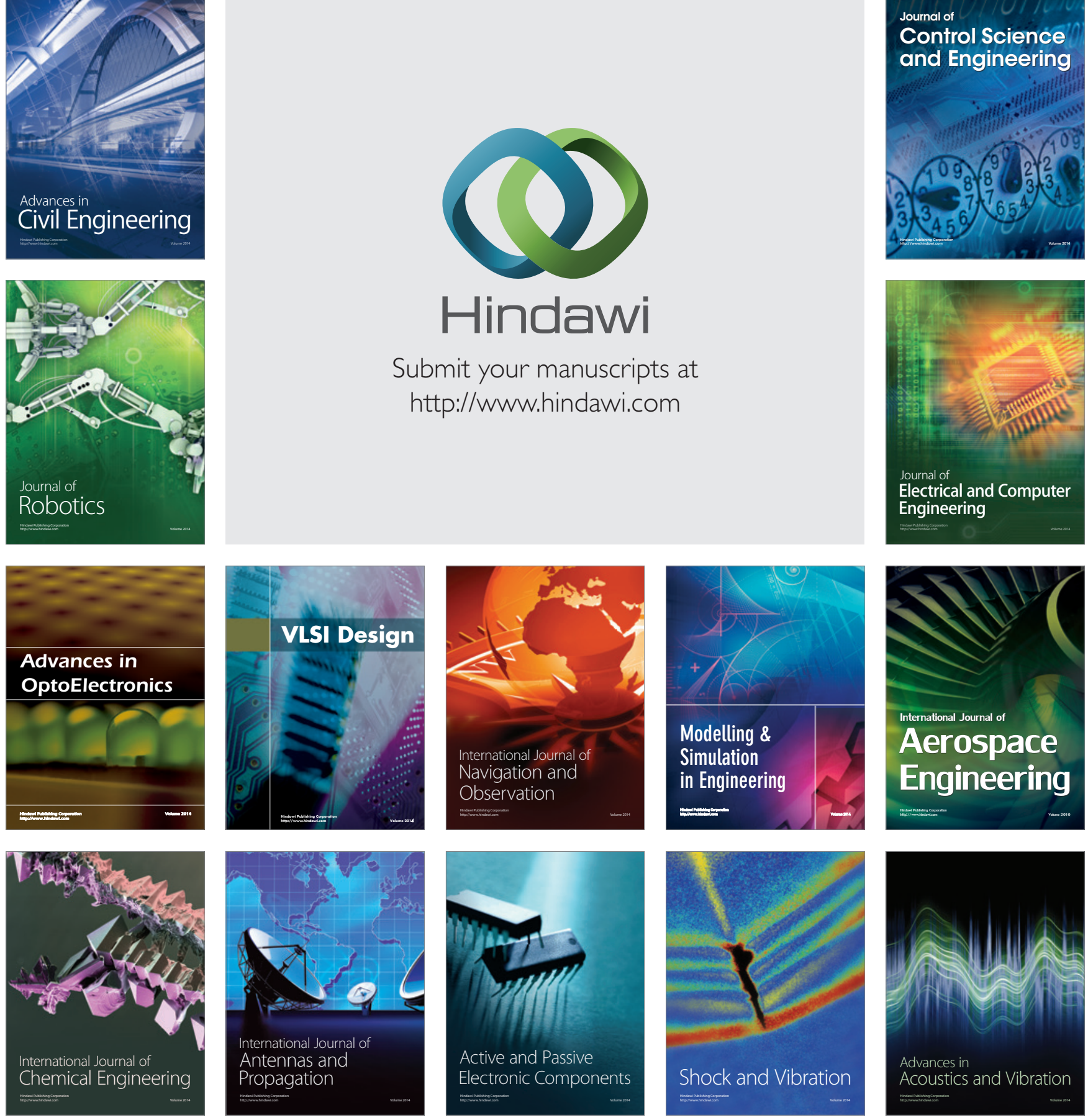